\title{
Sexualidad mágica y sagrada en la India Antigua: El tantrismo
}

\author{
M. ${ }^{\text {a }}$ TERESA ROMÁN LÓPEZ*
}

\section{RESUMEN}

El tantra es una manifestación especial del arte, de la religión y del sentimiento hindú. Estilos de vida, rituales, magia, mito, filosofía y un entramado de signos y símbolos emotivos convergen en esta visión.

Los libros básicos que los transmiten se denominan, asimismo, tantra, escritos en lengua sánscrita o vernácula. El tantra contiene muchos elementos arcaicos. Algunos son tan antiguos como las cuevas paleolíticas de Europa.

Se puede afirmar que el tantra representa un sistema práctico completo para orientar y enfocar la libido humana, fomentándola primero y alejándola después de los fenómenos pasajeros del mundo, para enfocarla hacia un objeto trascendente.

\section{SUMMARY}

The Tantra is a special manifestation of art, of the religion and the Hindu feeling ways of life, rituals, magic, miths, philosophy and a truss of emotive signs and simbols converge in this vision.

The basic books that transmit are colled, aswell, Tantra, they writte in sanscrit or "Vernacula" language. The Tantra contains a lot of arcaic elements. Some are as ancient as the Paleolitic caves in Europe.

\footnotetext{
* Departamento de Filosofía y Filosofía Moral y Política. UNED.
} 
It can be afirm that the Tantra represents a practic system complete to Oriental and considerer the human Libido encourgeing it first and removing it from the world passing phenomenons after, to considerer it to a transcedent objetive.

\section{INTRODUCCIÓN}

El tantrismo es una corriente de pensamiento que impregna todas las formas religiosas y filosóficas de la India: hay un tantrismo hindú, budista $y$ jainista.

El tantrismo es el resultado de factores mágicos, concepciones religiosas prearias ${ }^{1}$ e hindúes, cultos populares donde tiene un lugar preeminente todo lo esotérico y el acto de la iniciación.

El término tantra está relacionado con el concepto de tejer y con sus palabras familiares «hilo», «trama», «tela». En su origen, tantra es una palabra sánscrita y se refiere a la urdimbre de hilos en la cual se teje la trama para convertirse en una tela. Los practicantes del yoga ${ }^{2}$ utilizaron el término para representar la naturaleza entretejida del universo y nuestras acciones, la continuidad de causa y efecto, y la interdependencia básica de todo lo que existe. En este sentido, el lama Anagarika Govinda escribió lo siguiente:

«Tantra evoca el estado de entrelazamiento de todas las cosas y de todos los actos, la interdependencia de todo cuanto existe, la continuidad en las alternancias de causas y efectos, lo mismo que la continuidad en el desarrollo espiritual y tradicional, como un hilo que pasa a lo largo de todo el tejido de los acontecimientos históricos y de las vidas particulares" ${ }^{3}$.

Las doctrinas y la literatura que posteriormente se conocieron como tantra se fundamentan en la experiencia mística que entrelaza la mente del yogui al material sin costuras de la Realidad Suprema.

\footnotetext{
1 Véase M. T. RomÁN, "La magia hindú y su proyección hacia occidente en el mundo antiguo", Espacio, Tiempo y Forma, UNED, Madrid, 1995, pp. 86-92.

2 La palabra "yoga" se emplea de distintos modos. La referencia más típica es a los métodos de dominio de sí mismo y meditación, que en la tradición india adoptan diversas modalidades; así se puede hablar de yoga budista, jainista e hinduista. En sentido más restrictivo, el término se toma como designación de una de las seis escuelas ortodoxas de la filosofía hindú. En un sentido mâs amplio, el vocablo designa toda práctica encaminada a la liberación.

3 A. GovindA, Fundamentos de la mística tibetana, Eyras, Madrid, 1980, pp. 104-105.
} 
En el núcleo del tantra, hallamos la experiencia de un poder divino en el interior del hombre que es suceptible de activarse. Se afirma que el cuerpo es la sede de este poder, y, por consiguiente, el corazón de la práctica ritual. Los yoguis denominaron a este poder interno kundalini ${ }^{4}$.

En el tantrismo, el organismo humano se percibe como un microcosmos del cosmos. Los adeptos del tantrismo intentan modificar la conciencia para poder entender la naturaleza ilusoria de su sentido normal de la identidad y vivenciar de forma directa su unidad fundamental con el universo.

En el interior de la estructura psico-somática hay unos centros de energía psíquica llamados chakras (figura 1) que significa ruedas o lotos, aludiendo ambos términos respectivamente a su forma redonda y a su representación mediante el símbolo de una flor de loto. En los chakras se alojan divinidades concretas, con sus fuerzas psicológicas y espirituales únicas. Estos centros y sus correspondientes divinidades constituyen el fundamento de una complicada estructura de mito y ritual en el tantrismo.

Aparte del carácter primordial del sistema de chakras y la evocación del poder primigenio de la creación en los rituales de meditación, el tantrismo presenta otros elementos característicos. La visualización de diferentes divinidades la define de por sí. Un estudiante aprende a entonar los sonidos sagrados, imitar las posiciones corporales y gestos e identificarse con distintas divinidades en la meditación, mientras percibe sus estados de conciencia celestiales.

Si bien el tantrismo emplea deidades para simbolizar diferentes fuerzas espirituales y estados de conciencia superiores, el universo se visualiza como una acción espontánea de continua creación, emergiendo de un vacío uterino cargado de potencia! ilimitado. Este imponente vacío está

4 Según BLAY: "Kundalini es una energía que está dentro del Muladhara enroscada como una serpiente, dando tres vueltas y media sobre sí misma y obturando con su cabeza el canal de salida de Sushumna. Allí Kundalini yace dormida. Y todos los esfuerzos del Yoga tántrico se proponen neutralizar el funcionamiento de lda y Pingala, acumulando toda la fuerza posible en el Muladhara para activar esta energía dormida de Kundalini y hacerla ascender hacia arriba por el nadi central Sushumna, atravesando todos los chakras que encuentra en su camino y dinamizándolos también, hasta llegar al chakra superior Sahasrara. Pues, en el momento en que Kundalini consigue, en su ascenso, llegar hasta arriba, se produce la unión o éxtasis final o Samadhi, es decir, la realización, que es la meta suprema del trabajo yóguico". A. BLAY, Tantra Yoga, Iberia, Barcelona, 1986, pp. 26-28. 


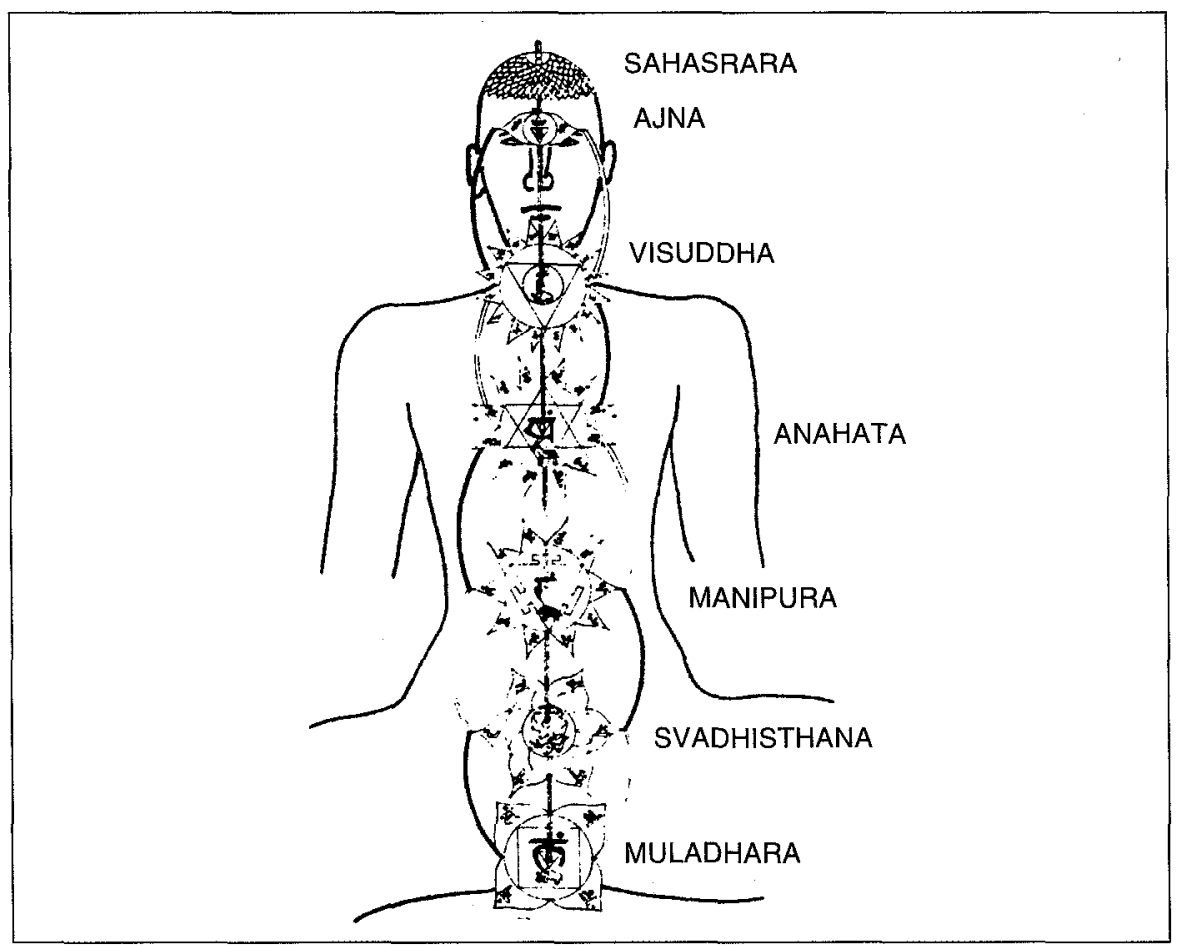

Figura 1. Los chakras.

unido con la conciencia pura y su cualidad espacial es fundamento inimitable del cual surge el universo fenoménico. Mientras las grandes tradiciones religiosas creen en una entidad superior, "Dios", creador, gobernante $\mathrm{y}$, por consiguiente, separado del cosmos, la Realidad Absoluta en el tantrismo se lleva a cabo en la meditación como un estado intrínseco del Ser-Conciencia.

Casi todas las vías espirituales se apartan del mundo material con el fin de ir más allá de la realidad cotidiana. Se apoyan en valores duales: el bien y el mal, la materia y el espíritu, etc. El tantrismo considera que esas mismas fuerzas cósmicas que dan origen al universo, residen en nuestro interior. No existe un mundo de cosas separadas. Las fuerzas que se cristalizan en el universo fenoménico son las fuerzas cósmicas sublimes, que pueden volver a su estado original. El tantrismo engloba cualquier elemento humano en nosotros. La energía del pensamiento, del sentimiento, del sexo y cualquier acción, es transmutada a través de medios hábiles. 


\section{TANTRA HINDÚ Y TANTRA BUDISTA}

\section{Desarrollo histórico}

Las raíces del tantra están incluidas en la temprana historia de la cultura india. El tantra hindú y el budista son los troncos principales de un árbol que maduró a partir de los cultos antiguos y tradiciones orales, y se extendió por Nepal, Tíbet, Mongolia, China, Japón, el Cercano Oriente y Occidente.

La imperturbable civilización de la antigua India dio lugar a que el tantra evolucionara desde las fecundas simas de la mente mitológica y se desarrollara a través de algunos de los más eminentes maestros espirituales de la tierra. Algunos aspectos de su mito y ritual hunden sus raíces en un período muy remoto ${ }^{5}$.

En la temprana cultura hindú se rendía culto al poder generador del universo como la Diosa Madre. Representada en un gran cantidad de artefactos hindúes, ella se halla con frecuencia ligada a los animales, cuyo valor sagrado y de culto se relacionaban con su fuerza y su virilidad sexual.

El acento en la fecundidad no se reducía a la diosa y a las figuras de animales. Algunas representaciones masculinas estaban sentadas en posturas yóguicas, mostrando tocados con cuernos y esgrimiendo falos erectos. Asimismo, los penes erectos tallados en piedra ponian en evidencia esta temprana veneración a las fuerzas generadoras de la naturaleza ${ }^{6}$.

Siva, que eventualmente se transformó en un importante dios en el tantra hindú, en realidad fue un desarrollo de estos cultos hindúes. Siva es mostrado en muchas ocasiones como la divinidad con cornamenta de los timbres hindúes, sentado en posición de yoga con el pene erecto. Su símbolo universal es un falo erecto (lingam) y su medio de transporte, un toro.

Un hecho de gran trascendencia en la historia de la India fue la invasión de los arios, alrededor del 1500 a. de C. Los arios trajeron con ellos un panteón de divinidades celestes, una importante casta sacerdotal que

\footnotetext{
5 En el complejo prehistórico de Pech-Merle en Francia, hay una cámara con emblemas femeninos que son muy similares a los que aún se adoran en los santuarios hindúes. Véase $P$. Rawson, Tantra: The Indian Cult of Ecstasy, Avon, New York, 1973, p. 7.

6 Véase M.T. ROMÁN, "La magia hindú y su proyección hacia Occidente en el mundo antiguo", Espacio, Tiempo y Forma, UNED, Madrid, 1995, pp. 88-92.
} 
recitaba himnos y llevaba a cabo rituales, y una bebida excitante que los arios ofrecían a las divinidades y que tenía un papel central en la liturgia: el soma?.

Los arios poseían una cultura guerrera y patriarcal. Mediante sus rituales y poderes mágicos intentaban manipular a las deidades. Con el paso del tiempo, sus ceremoniales se transformaron en simulaciones complejas de la totalidad del universo, y la casta sacerdotal se hizo muy poderosa.

La adoración de las diosas locales, procedente de cultos hindúes más tempranos, siguió evolucionando de forma autónoma y paralela a esta tradición védica. Se desarrollaron muchos cultos populares en torno a distintas diosas y modos de adoración. Como toda vida animal dimana del útero femenino, el cosmos era contemplado en forma mítica como procedente de la Diosa. Es ella la que simboliza la conciencia en el universo material y de los sentidos y, a su vez, la libera. De este modo, una mujer en quien la Diosa se hubiese manifestado era muy respetada y la relación sexual ritual con ella se conceptuaba como una iniciación a los misterios.

Estos ejercicios de culto se contraponían a la tradición védica. En tanto que en el tantra la energía sexual era venerada y se vivía como una forma de adaptación a los procesos cósmicos, la tradición védica propugnaba una contención represiva del poder sexual sagrado. Las enseñanzas ascéticas tenían mucho que ver con la posición social. Para un sacerdote o un miembro de las castas superiores, el acopio de este poder sagrado era de gran importancia puesto que, al parecer, éste colmaba el organismo con energía espiritual, y como consecuencia, se obtenían poderes suprahumanos.

El siglo vi a. de C. fue un período de reformas políticas y sociales en la cultura aria. Las prácticas de las religiones populares, por largo tiempo dominadas por la tradición védica, surgieron y se mezclaron con nuevas formas de pensamiento. Estas formas ponían el acento en el esfuerzo personal antes que en el dogma y se apoyaban en la experiencia de instructores que ejemplificaban los frutos de sus prácticas espirituales. Grandes maestros como Siddharta Gautama, fundador del budismo, y Mahavira, el profeta de la religión jainista, atrajeron a muchas mentes inquietas.

Véase P. DE FELICE, Venenos sagrados. Embriaguez divina, Felmar, Madrid, 1975, pp.197215. 
Con el transcurso del tiempo, la tradición védica adoptó muchas de las prácticas meditativas, los dioses y los elementos filosóficos de estas religiones populares. Lo que actualmente se denomina yoga ${ }^{8}$ es la consecuencia de este hecho.

En el yoga, las divinidades populares personales sustituyeron a Brahma, la deidad védica suprema e impersonal, que simbolizaba el Absoluto. Visnú y Siva, por ejemplo, se transformaron en dioses personalizados y centros de concentración para los sistema yóguicos que incorporaban los métodos tántricos antiguos. Estos sistemas fueron el vehículo del tantra hindú.

El budismo fue otra de las consecuencias del renacimiento religioso de la India en ese período. El príncipe Siddharta Gautama conocido como el Buda ${ }^{9}$ dejó su familia y riquezas, y partió en busca de una solución para el sufrimiento humano. Según la tradición alcanzó la lluminación tras una larga meditación bajo una higuera. El núcleo de las enseñanzas del Buda fueron las «Cuatro Nobles Verdades» y el «Noble Sendero Óctuple». Sus enseñanzas fueron canonizadas por los discípulos que le sobrevivieron en la corriente denominada, Hinayana (Pequeño Vehículo). Quinientos años más tarde, una enseñanza mucho más expandida se conoció como la corriente Mahayana (Gran Vehículo). Durante los siglos posteriores, el budismo fue incorporando gran cantidad de elementos tántricos.

El tantra budista ${ }^{10}$ evolucionó de modo lento y secreto durante un milenio, desarrollándose completamente entre los siglos VIII y XII. Fue difundido por sabios excéntricos, siendo los más célebres los ascetas melenudos, que se burlaban de las rígidas tradiciones monásticas y las estrechas

8 El sistema yóguico era una práctica por la cual la mente, el cuerpo y los sentidos podían ser unidos a la naturaleza espiritual. Así se obtenía un estado supraconsciente, eliminando la diferencia entre el sí mismo individual y el Sí Mismo universal.

9 Véase M.T. ROMÁN, "Buda: un personaje para la historia del antiguo oriente", Espacio, Tiempo y Forma, UNED, Madrid, 1994.

${ }_{10}$ Hay una gran controversia entre budistas e hindúes acerca del origen del tantra. Algunos investigadores afirman que el tantra budista evolucionó del tantra hindú. Los budistas sostienen que el Buda histórico fue el artífice del tantra. Los textos budistas tempranos indican que, como mínimo, Siddharta conocía el sistema de chakras y el fuego interior. Es posible que fuera instruido en las antiguas prácticas tántricas y posteriormente las revisara o las reinterpretara. Asimismo es probable que algunos de los métodos más elaborados de meditación tántrica budista no fueran introducidos en el canon budista hasta varios siglos después de la muerte del Buda. Con el advenimiento del Gran Vehículo, el término Buda se refirió más al potencial de la Mente-lluminada inherente dentro del ser humano, que al Buda. 
convenciones del sistema hindú de castas, para practicar la «Sabiduría Loca». Estos yoguis con grandes poderes gozaban de sus experiencias místicas mientras se divertían con la realidad mundana; enseñaban sobre todo con ejemplos; la libertad existencial de sus vidas conducía a menudo a conductas y hechos que hacían añicos las estrictas estructuras psíquicas de los alumnos con metáforas poderosas y nada usuales.

El tantrismo llegó a China en el siglo vill y de allí pasó a Japón.

En la India propiamente dicha el budismo se extinguió alrededor del siglo XIII. En este período, el budismo tántrico fue trasplantado con éxito al Tíbet.

\section{Períodos del tantra budista}

El tantra budista, puede dividirse en tres fases. La primera se denomina mantrayana. Tuvo su inicio en el siglo iv y su desarrollo hacia el $500 \mathrm{~d}$. de $\mathrm{C}$. Enriqueció al budismo con las aportaciones de la tradición mágica, usándolas con el propósito de favorecer la búsqueda de la iluminación. Así, muchos mandalas, mantras, mudras y nuevos dioses penetraron en el budismo de modo más o menos asistemático.

Esta primera etapa fue seguida, después del 750, por una sistematización, denominada Vajrayana («Vehículo del Rayo" o "Vehículo del Diamante»), que compaginaba todas las enseñanzas previas con los cinco Budas trascendentes (Amitabha, Amoghasiddhi, Akshobhya, Ratnasambhava y Vairocana).

En el transcurso del tiempo aparecieron nuevas corrientes. Hacia el siglo $x$, surge Kalachakra, "Rueda del Tiempo», que se caracteriza por un gran sincretismo y el énfasis en la astrología. Se ha llegado a afirmar que el sistema Kalachakra se gestó en el misterioso país de Shambhala ${ }^{11}$.

El tantrismo trató de situar en un puesto destacado a todos los duendes, ogros, espíritus, fantasmas y demonios que rondaban la imaginación del pueblo, así como a los rituales mágicos tan estimados por todos las poblaciones nómadas y agrícolas. Este avance en la popularización de la religión tenía como fin proporcionarla un fundamento social más consis-

11 Ver W.Y. Evans-Wentz, El Libro Tibetano de la Gran Liberación, Kier, Buenos Aires, 1977, p. 112. 
tente. Sin embargo, en el seno de los grupos minoritarios se había producido la gran diferencia de que los no budistas empleaban la magia para obtener poder, en tanto que los budistas lo utilizaban para alejarse de todo poder ajeno a su propia y auténtica entidad.

La finalidad del tantra es la budeidad o el despertar aquí y ahora, obtenida de forma milagrosa merced a una manera nueva, rápida y simple. El santo ideal es en este caso el Siddha, el mago, que tiene sus poderes maravillosos completamente desarrollados.

Respecto al sistema de enseñanza, el tantrismo presenta una vasta literatura canónica, los tantra, que son libros secretos dirigidos a un pequeño número de personas entrenadas por un maestro, o instructor; están escritos en un lenguaje oscuro e ininteligible, incomprensible sin un instructor iniciado en sus doctrinas.

Las bases de estas nuevas convenciones literarias se reflejaban ya en el grupo budista yogachara. Este grupo sistematiza las vivencias obtenidas en el desarrollo de un trance meditativo muy profundo, y los adeptos creían que las visiones que surgían durante el trance presentaban un mayor grado de realidad que lo que se denomina "hechos", fechas y lugares, sujetos, nombres y biografías. Asimismo, el sistema yogachara mostró un gran interés por las formas más enigmáticas de transmisión de información. De hecho, las ideas y los métodos tántricos se gestaron en la secta yogachara.

El desarrollo del mantrayana fue en un principio una respuesta lógica ante las tendencias históricas contrarias que ponían en peligro el budismo en la India. En su defensa y como protección, los seguidores del mantrayana pusieron en movimiento cada vez más a los poderes mágicos y arcanos, y recurrieron a la poderosa ayuda de más y más seres mitológicos, cuya verdadera realidad se manifestaba en los trances meditativos. Se puso especial énfasis en las divinidades "coléricas", como los «Protectores del Dharma", que son compasivos, pero que adquieren una apariencia horripilante para proteger a los fieles.

En el 400 d. de C. se veneraba a Tara y a Prajñaparamita como bodhisattvas (santos próximos al estado de Buda) celestes. Posteriormente, los practicantes de la meditación mística de altos vuelos desplegaron un panteón completo de divinidades femeninas, como Cunda, Usnisavijaya, Vajravarahi, Vasudhara y otras. Los practicantes de las artes mágicas eran especialmente devotos de las «reinas del sagrado saber» y de los «cami- 
nantes del cielo"; y la gente en general era inducida a dirigirse para sus intereses personales concretos a diosas que concedian niños, protegían de la viruela, etc.

Hacia el 700 d. de C., los denominados tantra «de izquierda», incorporaron a los consortes de Budas y Bodhisattvas. Recibían el nombre de vidyas y prajñas. El culto de las vidyas iba con frecuencia unido a un ritual aparentemente erótico.

La creencia en lo esotérico y en la magia ha sido siempre un aspecto importante del budismo, aunque más bien como reconocimiento de un hecho existente que como un tema de importancia práctica inmediata. Sin embargo, conforme la fuerza espiritual del Dharma ("Enseñanza») iba debilitándose y se notaba la adversidad progresiva de la historia, se produjo un mayor grado de confianza en la magia para protegerse de los aspectos negativos de la vida y obtener favores.

En el $500 \mathrm{~d}$. de C., se sirvieron de los mecanismos habituales de la magia, desde rituales hasta diagramas y círculos mágicos. Estos se empleaban para proteger la vida espiritual de la clases altas y para darle a la gente, desprovista de espiritualidad, lo que querían. Los gestos rituales (mudras) robustecían con frecuencia la operatividad de los conjuros.

Se encontraban asimismo los círculos mágicos (mandalas) ${ }^{12}$, conocidos en todas partes desde los tiempos paleolíticos. El mandala es una representación compleja del universo fenoménico comprendido en su totalidad, tanto en el plano cósmico como en el plano psíquico. Su conocimiento teórico y su práctica pueden llevar al practicante que lo descubre bajo la dirección de un instructor, a la reintegración de su conciencia, mediante la revelación del juego secreto de fuerzas que operan en él $y$ en el cosmos.

Un mandala puede consistir en un dibujo trazado en tierra con la ayuda de granos de polvo o de fibras, unos y otros coloreados; cuando ha cumplido su misión, se borra. Hay también mandalas más duraderos. Un mandala incluye un círculo exterior y uno o más círculos concéntricos que encierran a un cuadrado dividido en cuatro triángulos: en medio de cada uno de los triángulos, lo mismo que en el centro del mandala, hay otros círculos que contienen los rostros de las deidades o su emblemas. Este es-

12 Ver G.Tuccl, Teorla y práctica del mandala, Dédalo, Buenos Aires, 1975. 
quema iconográfico es susceptible de infinitas variantes; algunos mandalas ostentan la apariencia de un laberinto, otro, las de un palacio, con sus murallas, sus torres, sus jardines.

La elaboración de los mandalas y la invocación de las divinidades estaban sometidos a normas rigurosas y ceremonias rituales establecidas ${ }^{13}$.

La explosión creativa del tantrismo primitivo condujo a un laberinto de teorías acerca de las fuerzas cósmicas y espirituales, y fue el Vajrayana («Vehículo del Diamante») el que sistematizó ese grupo incipiente de tradiciones que habían surgido.

El vajrayana adoptó una división en cinco ${ }^{14}$ tipos de todas las fuerzas cósmicas, cada una de las cuales estaba, en cierto sentido, regida por una de las cinco divinidades. Una intrincada estructura de correspondencias mágicas, transformaciones, identificaciones y transfiguraciones unía a continuación todos los hechos y fuerzas cósmicas con estas cinco «familias". Se creía que el cuerpo era un microcosmos que incorporaba al cosmos y el instrumento para percatarse de la verdad, sobre todo a través de prácticas que formaban parte del Hathayoga ${ }^{15}$.

Nos hallamos frecuentemente con referencias a los paralelismos entre lo tocable, lo audible y lo visible, y todo ello con el fin de ligar los poderes del cuerpo, el habla y la mente con el propósito de obtener la meta final de plenitud.

Se ha definido al Vajrayana como «el arte de vivir que nos posibilita el poder emplear cada actividad del cuerpo, el habla y la mente como ayuda en el Sendero de la lluminación». No obstante, el auténtico significado de las doctrinas del Vehículo del Diamante es difícil de determinar, porque en él ha llegado a ser frecuente hacer que lo más elevado se muestre como lo más vulgar, lo más excelso como lo más profano; el saber más sensato está oculto tras las paradojas más extravagantes.

\footnotetext{
13 Véase H. von Glasenapp, Misterios budistas, Ediciones Esotéricas, Buenos Aires, 1974, pp. 101-102.

14 El número cinco juega un papel importante en la India. Hay cinco sentidos, cinco elementos, cinco puntos cardinales, etc. En el budismo existe, por otro lado, la doctrina de los dharmas (factores de la existencia) que dan a dicho número un significado especial. Finalmente, el denominado Gran Vehículo establece que la sabiduría de la que está provisto el Buda comprende cinco elementos.

15 Es uno de los métodos del Yoga que se ocupa del aspecto fisiológico. Al Hatha Yoga pertenecen la práctica de diversas posturas y la respiración regulada.
} 
Nos encontramos ante un ataque consciente contra la exagerada intelectualización del budismo en aquellos tiempos. En definitiva, la profusa iconografía sexual tenía como meta agitar el puritanismo de los monjes. La iluminación, consecuencia de la combinación del conocimiento y la variedad de recursos, se representa como la unión de un varón y una mujer en el éxtasis del amor. El instante en que se unen en la iluminación es el inefable goce supremo.

La dinastía pala de Bengala fue la que determinó la historia del budismo durante siglos mediante su apoyo a las grandes universidades budistas. Entre los siglos $\mathrm{V} \mid$ y IX, Nalanda había sido el centro vivo de pensamiento de todo el mundo budista. Bajo la dinastía pala se fundaron nuevos centros en el Este de la India; éstos fueron los puntos nucleares desde los que la cultura budista irradió a toda Asia durante los siglos IX al XII.

\section{La literatura tántrica}

Los tantra como textos y su doctrina, el tantrismo, integran, después de los Veda ${ }^{16}$, los Upanishad ${ }^{17}$, los Purana ${ }^{18}$, etc., las bases de la "religión eterna" del hinduismo. Su tema central es la Sakti o divina energía creadora, que, personificada como Devi o «la Diosa», constituye la forma femenina o "esposa» de un aspecto de Dios, sobre todo como esposa del dios Siva.

En su mayor parte, la voluminosa literatura tántrica está escrita en sánscrito y no ha sido traducida a ninguna lengua europea. Se calcula en un millar el número de tantras, generalmente anónimos, cuya redacción continúa en la época contemporánea.

Al parecer se compusieron en diferentes épocas y lugares de la India, más o menos como enciciopedias de ritual y filosofía tántricas, y que fueron copiados, corregidos y aumentados en varias ocasiones. Los más an-

${ }^{16}$ La literatura védica comprende cuatro colecciones que son: el Rigveda, o "Veda de las estrofas"; el Samaveda, o "Veda de las melodías"; el Yajurveda, o "Veda de las fórmulas" el Atharvaveda, o "Veda de los encantamientos"; estas cuatro constituyen el Veda propiamente dicho.

17 Son los textos que constituyen la parte final de la "Revelación" y sientan los fundamentos del Vedanta, las conclusiones filosóficas procedentes de los Veda.

18 Textos de historia legendaria. Fueron compuestos en el siglo $\| \mathrm{d}$. de C. Guardan el vago recuerdo de los eventos acaecidos en el período védico tardío. 
tiguos se recopilaron en el año 600, pero algunos de los más importantes e influyentes fueron redactados al final de la Edad Media.

Los tantra más conocidos son el Mahanirvanatantra o Tantra de la Gran Liberación, y el Kularnava o el Océano de la doctrina Kaula, libro de base de la escuela de igual nombre, que representa las doctrinas tántricas extremas; el Shaktisangana, el Rudrayamala, el Tantrakaumudi, el Tantrasattva, el Kalika, el Sharadatilaka, el Syama Rahashya y el Mantra Mahodadhi ${ }^{19}$.

Los textos tántricos se presentan por lo general en la forma de un diálogo entre Siva y Sakti. Tienen por objeto elevar a divina perfección la totalidad del ser humano enseñándole a despertar por medio de determinados ritos y prácticas de meditación la energía cósmica que lleva en su interior.

El esoterismo es un rasgo esencial del tantrismo: en él, la verdad es transmitida "de boca en boca», por medio de una iniciación precedida de un largo y severo postulado. La literatura no es más que un comentario acerca de esta enseñanza fundamentalmente oral. Al mismo tiempo, para rehuir la curiosidad, ha sido redactada en un estilo de una oscuridad refinada que, mediante un juego de correspondencias entre realidades psíquicas y realidades eróticas, abre el campo a múltiples significaciones.

Los tantra budistas son obras de un carácter muy especial, en las que el culto de los divinidades extravagantes está unido al sistema monoteísta y al resto de las fases del desarrollo del budismo septentrional, es decir: a la teoría de un Buda supremo y a la de los Budas y Bodhisattvas sobrenaturales.

Todos estos personajes son en los tantras suceptibles de un culto cuyas pautas están indicadas en estos tratados, y muchos de estos libros son repertorios de normas redactadas como orientaciones para los devotos en el arte de diseñar y ordenar los círculos mágicos y otros símbolos de este tipo destinados a recibir las imágenes de los dioses mencionados. Los sacrificos y las oblaciones que se les tributan con el fin de obtener sus favores y clemencia, así como las plegarias e himnos que se recitan y entonan en su honor, desempeñan un papel relevante en estos tratados.

19 Véase J. Rivière, El pensamiento filosófico de Asia, Gredos, Madrid, 1960, p. 125. 
Por último, la literatura tántrica incluye fórmulas mágicas, auténticos sortilegios, al parecer elaborados por las propias deidades de que se trata y cuyos nombres llevan por regla general y tienen la propiedad de librar del cualquier trance peligroso al poseedor de estos tratados.

Estas concepciones, junto con la veneración de las energías femeninas de los Budas y Bodhisattvas y a la de las otras deidades conocidas por los sivaítas ${ }^{20}$, se encuentran en estos tratados especialmente asociadas al culto del Buda Shakyamuni y a las teorías cuya enseñanza el budismo intenta popularizar. El propio fundador del budismo está positivamente representado en estos textos como fundador del ritual y de las oraciones mágicas de los tantra.

En principio, los tantra budistas se dividen en cuatro grupos: Kriya-tantra, Carya-tantra, Yoga-tantra y Anuttara-tantra; los dos primeros tratan sobre los rituales y los otros dos sobre los procesos yoguis mediante los que se llega a la verdad suprema. Casi todas las obras tántricas incluyen indicaciones rituales, 10 mismo que instrucciones de orden yogui y fragmentos filosóficos.

Según el budismo tibetano, las cuatro grupos de tantra estarían conectados con los principales tipos y temperamentos humanos: los tratados del kriya-tantra convienen a los brahmanes y a los que se dedican al ritualismo; los carya-tantra se recomiendan principalmente para los hombres de negocios, y así sucesivamente. Cada clase está dirigida a un tipo particular de practicante y lo que las diferencia es la intensidad de energía de deseo que el practicante es capaz de emplear para el camino espiritual.

Una de las obras más antiguas es el Guhyasamaja o Tathagataguhyaka, que data de la época de formación del tantra en el budismo. Pero los tantras budistas encuentran sus antecedentes en la literatura de la Prajñaparamita, en la cual hay algunas referencias a sortilegios propios del método tántrico. Otro importante texto es el Mahavairocana-Sutra. En éste se desarrolla la idea del Buda Mahavairocana, según la cual, el Buda, que es idéntico con el universo, es la última realidad de éste. Estas obras fundamentales van acompañadas de una abundante literatura de tratados, manuales y comentarios atribuidos a maestros diversos.

20 El sivaísmo es una de las grandes orientaciones del culto divino en el hinduismo moderno. Los sivaítas consideran a Siva como la divinidad suprema, creadora, destructora y conservadora del universo, y sólo a él rezan y rinden culto. 


\section{LA DOCTRINA TÁNTRICA}

\section{El tantra hindú}

El tantra hindú está constituido por símbolos y metáforas procedentes de cultos antiguos. Por consiguiente, empezaremos por allí antes de pasar a ver de qué manera estos símbolos y metáforas entraron a formar parte del budismo.

En una de las modalidades de tantrismo hindú, la Realidad Absoluta está personificada como el dios Siva. Los antiguos yoguis concebían al cuerpo del universo como el amante del dios Siva. Se utilizan diversos nombres para expresar las distintas formas que adopta Siva, pero en general se la conoce como Sakti. Cuando ella está dando forma a lo amorfo y limitando el infinito, se llama Maya Sakti. El término maya procede de la raíz sánscrita ma, que sinifica medir, formar, mostrar. Mediante su imaginación divina, Maya Sakti evoca la gran ilusión del cosmos, envolviendo a la conciencia pura de diferentes estratos materiales. Esta perspectiva no quiere decir que el universo no exista; pero, su auténtica naturaleza está encubierta, como consecuencia de mentes confusas.

Asimismo se venera a Sakti como la que desvela la verdad y la gran liberadora. Todo lo que ella trae a la existencia temporal, algún día volverá a su esencia primigenia. Esta función de la diosa está personificada como Kali, la que crea temor reverente.

La imagen sexual de Siva y Sakti como amantes sugiere la interacción mutua. Aunque en apariencia estén separados, en realidad, son dos aspectos complementarios de una sola unidad. Esta divinidad suprema bisexual es tanto temporal como eterna. Siva es el todo sin límites y Sakti es la creciente convergencia de partes que constituyen el todo; Siva es trascendente e invariable y Sakti está relacionada con los fenómenos y es variable.

Philip Rawson describe la perspectiva tántrica del universo como una red entretejida de vibraciones o resonancias sutiles. Originándose en la «sustancia» más sutil de la creación, estas configuraciones vibracionales se mezclan y entrecruzan hasta que parecen solidificarse. El sonido-sustancia genérico proviene de las tobilleras de Sakti, que tintinean mientras baila. Al ser cada vez más intrincados y palpitantes los ritmos de su danza, el hilo del cosmos se teje en siete grandes capas de densidad ${ }^{21}$.

21 Véase P. Rawson, ob. cit., p. 196. 
Los siete chakras del microcosmos humano (grandes centros de energía a lo largo de espina dorsal) están correlacionados con esta división en siete macrocosmos.

El séptimo chakra (figura 8), en la coronilla de la cabeza, se relaciona con la unión original de Siva y Sakti. En el sexto chakra (figura 7), en el centro de la cabeza, Sakti se ha separado de Siva y ha creado un reino de la mente (manas). Los cinco chakras restantes (figuras $2,3,4,5,6$ ), representan cristalizaciones progresivas simbolizadas por los cinco elementos: éter, aire, fuego, agua y tierra. Cada fase es más densa que la anterior, ya que se contrae del elemento previo, hasta que se forma la solidez del elemento tierra.

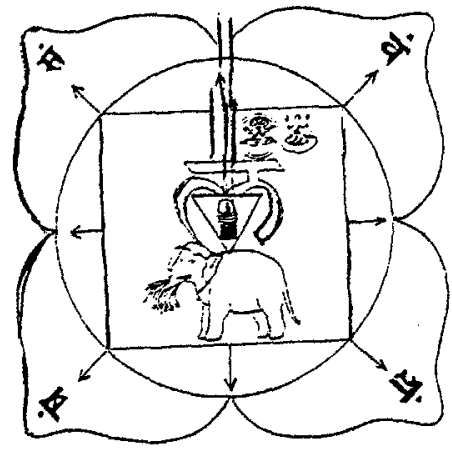

Figura 2. Representación esquemática del chakra Muladhara.

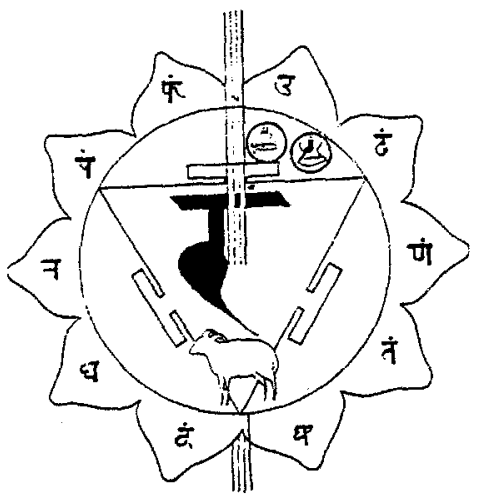

Figura 4. Representación esquemática del chakra Manipura.

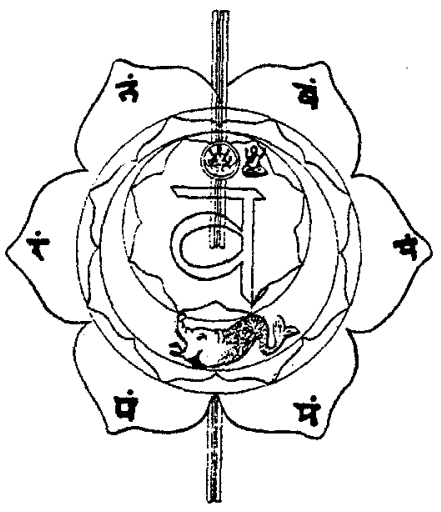

Figura 3. Representación esquemática del chakra Svadhistana.

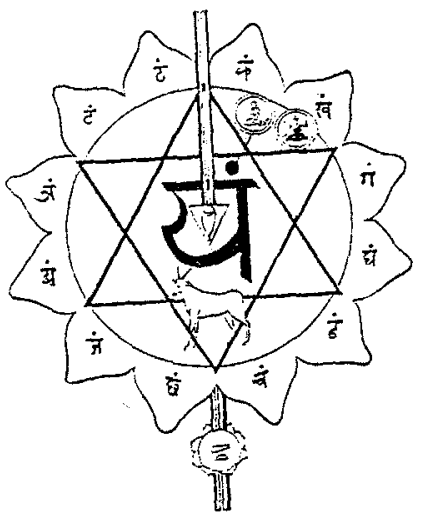

Figura 5. Representación esquemática del chakra Anahata. 


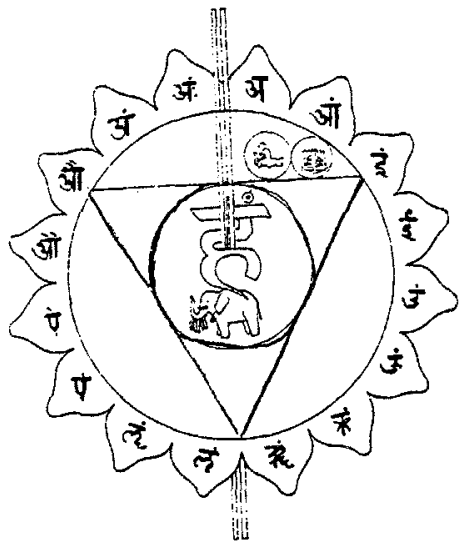

Figura 6. Representación esquemática del chakra Vishuddha.

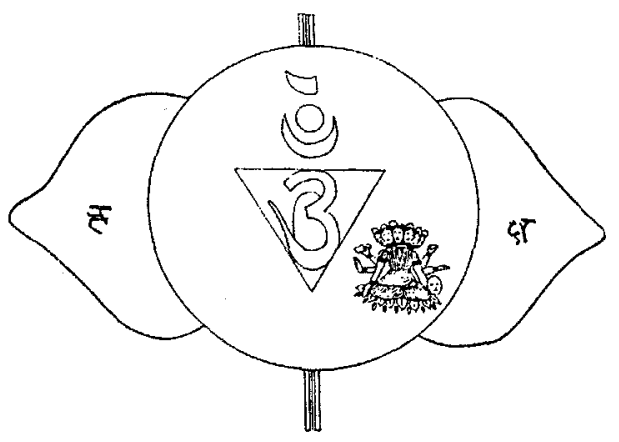

Figura 7. Representación esquemática del chakra Ajna

Una vez que Sakti ha concebido el universo, entra en un estado de letargo en las simas del mundo de la materia. La palabra sánscrita kundalin quiere decir «aquello que está enrollado o en forma de espiral en la naturaleza" y está referido a las disposiciones de energía en espiral que se encuentran en el universo natural. Al añadírsele la terminación larga $l$, se convierte en Kundalini, un sustantivo femenino que quiere decir «serpiente». Una serpiente descansa enroscada y - como un elástico- puede liberar su energía potencial cuando embiste. La mente mitológica del tantra integró estos elementos en la personificación de Kundalini Sakti, el poder primordial aletargado en la naturaleza. En el holograma del cuerpo-mente ésta reposa en el elemento tierra.

El flujo involuntario de Kundalini penetrando en el séptimo chakra se fragmenta en tres conductos en el sexto chakra. En el individuo corriente, Kundalini discurre por los conductos derecho e izquierdo, confiriendo conciencia a los órganos de los sentidos y a las facultades que sustentan la ilusión del universo.

En tanto que Kundalini repose en este estado, las vidas de los seres humanos están dirigidas por la acción ofuscada de los instintos, los deseos, y las ideas del propio yo. Se puede apartar esta energía divina de los mecanismos del cuerpo-mente y llevarla de nuevo por el conducto central. Cuando esto sucede, la Kundalini vuelve al estado vigil. Subiendo por la mente, se manifiesta en cada uno de los chakras para desvelar estratos de conciencia cada vez más profundos. 


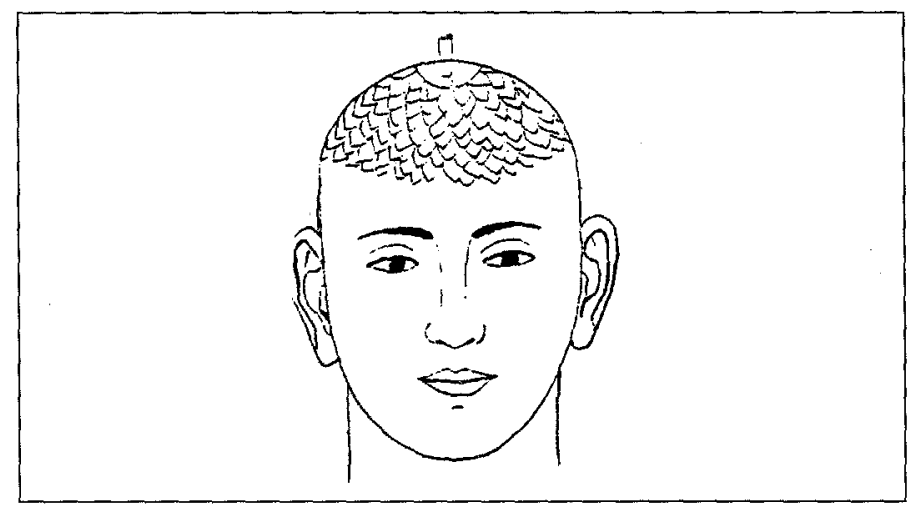

Figura 8. Representación esquemática del chakra Sahasrara.

Finalmente, nuestra conciencia escapa a las restricciones somáticas y comparte el placer divino de la unión sexual entre Siva y Sakti. Esta es la Gran Dicha y Sabiduría que, según el tantra, es el fundamento del ser y el objetivo más importante que hay que obtener.

El lenguaje y las imágenes de unión sexual se emplean aquí para referirse al éxtasis místico que alcanzaron los antiguos yoguis como consecuencia de sus entrenamientos. En las mentes mitológicas de estos yoguis, la energía sexual del microcosmos los ligaba de forma directa con los poúeres creativos del macrocosmos. La energía sexual era sagrada y se gozaba en un ritual, en el que los adeptos, hombres y mujeres, reunidos de noche en círculo, consumían las cuatro sustancias: alcohol, pescado, carne y un afrodisíaco hecho de granos resecos, y después se entregaban al acto sexual (maithuna) ${ }^{22}$.

No obstante estas prácticas, efectivas entre los adeptos del tantra de la mano izquierda, sólo se realizan de modo simbólico entre los adeptos del tantra de la mano derecha.

Por medio de este ritual, las parejas participantes transforman las tendencias al frenesí y a la gratificación sexual aprendiendo a contemplar a la deidad en todas las cosas. El coito era empleado para despertar la Kundalini, en tanto que las parejas se identificaban con Siva y Sakti.

22 Maithuna es conocido desde la época védica, pero será el tantra el encargado de transformarlo en herramienta de salvación. M. ELIADE, Yoga, inmortalidad y libertad, La Pléyade, Buenos Aires, 1988, pp. 245-256. 


\section{El tantra budista}

En el tantra budista hallamos muchos de los símbolos, divinidades, rituales y ejercicios meditativos del tantra hindú, pero con significados diferentes ${ }^{23}$.

Los requisitos principales para la práctica del tantra búdico son: la renuncia, la actitud iluminada y la visión correcta.

La renuncia significa eliminar la creencia en la identidad individual. Según el lama Yeshe:

«El desarrollo de la verdadera renuncia supone el no tener que depender ya de los placeres sensoriales para obtener la felicidad final» ${ }^{24}$.

El Buda Shakyamuni afirmó que un individuo era un compuesto de cinco elementos (skandha) ${ }^{25}$ : corporeidad (rupa), sensaciones (vedana), percepciones (samjña), formaciones mentales (samskara) y conciencia (vijnana). Lo que se denomina el sí-mismo es solamente estos cinco elementos moldeados por los hechos pasados y los deseos. A diferencia del tantra hindú, que postula un sí-mismo eterno (atman), el budismo dice: "anatman», "no atman», sin alma, sin «yo» a descubrir, sin sí-mismo. Según esta doctrina, la creencia en un sí-mismo es el origen del sufrimiento.

La actitud iluminada se refiere al ideal del Bodhisattva, que cambia la motivación de obtener la iluminación desde un beneficio personal a una de compasión por todos los seres. Esta motivación suprema se conoce en la terminología budista como bodhicitta.

La visión correcta se basa en la comprensión de la verdadera forma en que existe el mundo fenoménico. Todos los fenoménos son efímeros, carentes de autoexistencia y dependientes de otros fenómenos temporales. En el budismo se llamó originación interdependiente a la génesis de todos los fenómenos desde otros factores efímeros, y no desde una única entidad autoexistente (como Dios) ${ }^{26}$. La Realidad Suprema es la Vacuidad ${ }^{27}$ indefinible e inmutable de la cual todo emerge y desaparece.

\footnotetext{
23 Véase A. GovindA, Fundamentos de la mística tibetana, Eyras, Madrid, 1980, pp. 107-110.

24 Lama YESHE, Introducción al tantra, Dharma, Novelda (Alicante), 1987, p. 57.

25 Véase W. Rahula, Lo que el Buddha enseñó, Kier, Buenos Aires, 1990, pp. 40-50.

26 Ver Geshe L. TSULTRIM, El adiestramiento mental y los doce vínculos de originación interdependiente, Dharma, Novelda (Alicante).

27 Véase G. RABTEN, Echoes of Voidness, Wisdom Publications, London, 1986.
} 
La existencia constante de cualquier individuo es la consecuencia del deseo y la ignorancia. La ignorancia de la temporalidad de toda existencia conduce al deseo de mantener la identidad individual. El deseo provoca la aparición de los agregados o factores de la existencia y empuja al individuo a buscar gratificación en aquello que es temporal. Estos intentos siempre acaban en sufrimiento y frustración. En el budismo, la liberación acontece cuando terminan la ignorancia y el apego.

Según el pensamiento budista, somos el producio de nuestras acciones, positivas o negativas (karma). Nuestro aspecto físico agradable, nuestra salud o nuestra pureza mental, son la consecuencia del karma positivo, en tanto que los problemas y los infortunios tienen que ver con el karma negativo, que se desarrolla debido a la ilusión y es el resultado de un espíritu no disciplinado.

Es pues imprescindible aleccionar a ese espíritu disperso y huidizo, utilizando métodos de concentración mental para frenar esa corriente de pensamiento, depurando de este modo el espíritu de sus elementos negativos. Sin embargo, cada sujeto es una entidad única y sus necesidades son distintas. Para desarrollar esas aptitudes psico-físicas que ayudan a conseguir el estado último, existen cuatro disciplinas tántricas, los cuatro grupos en los que se encuentran divididas la enseñanza, la práctica y la literatura.

Las prácticas y las visualizaciones son distintas en cada uno de los cuatro niveles denominados: la acción litúrgica, la práctica, el yoga y el grupo superior.

Si consideramos a la deidad como una entidad suprema, percibiéndola como una identidad personal totalmente diferenciada a quien por tanto podemos hacer ofrendas para conseguir sus favores, al tiempo que nos la representamos de forma sensible, podemos hablar de acción litúrgica. Al considerarla al mismo nivel que nosotros, pero percibiéndola también como una identidad personal diferenciada, hemos llegado a la práctica. $Y$, si nos contemplamos a nosotros mismos como siendo la deidad, invocando su sabiduría trascendental, que llega a fundirse en nosotros hasta tal punto que, en tanto dura la meditación, somos uno con ella, nos encontramos en la etapa de yoga tantra.

Por último, si descubrimos y realizamos nuestra verdadera naturaleza, absolutamente idénticas e inseparable de la deidad, hemos conseguido el estado último, llamado anuttarayoga. 
El Bardo Thodol o El Libro Tibetano de los Muertos ${ }^{28}$, representa uno de los soportes del modelo tántrico budista. Bajo la apariencia de una experiencia de muerte, describe las dimensiones de la mente y la vía de la liberación en forma de metáfora. La cosmología del citado libro se fundamenta en cinco Budas primordiales. Estos cinco Budas centrales se relacionan con los cinco elementos cósmicos (relacionados con los agregados o componentes del individuo) y, por tanto, con los cinco chakras del mapa budista tibetano del cuerpo psíquico.

Las cinco energías-sabidurías se irradian desde el Vacío y se dividen para posibilitar todas las creaciones mentales. Cuando el proceso es revertido en la meditación, su sabiduria conquista las ilusiones de nuestra percepción mundana del cosmos.

Para encuadrar el esquema de los cinco Budas primordiales, los budistas a menudo mezclan las funciones del primer y segundo chakra y las del sexto y séptimo chakra. Cada uno de los cinco Budas representa una clase de percepción errónea (relacionada con un chakra concreto) y su energía-sabiduría antídoto.

Los cinco chakras del tantra budista manifiestan distintos aspectos de la mente. La energía vital (prana) se relaciona con la respiración y con la mente. Esto significa que a cualquier estado anímico corresponderá una clase de prana, que con frecuencia se refleja en el carácter de la respiración. Por consiguiente, la mente y el prana están unidos en la acción. El prana de cada chakra se estimula mediante ejercicios de meditación y respiración. Como resultado se traen a la conciencia emociones reprimidas y distintos estados de ánimo inconscientes.

El hecho de controlar los pranas es para purificarlos de sus ofuscaciones mentales-emocionales, guiándolos hacia el canal central, donde este aliento vital alimentará el fuego interior. Al agitar la energía vital, el elemento mentalemocional de cada chakra se purifica y se convierte en su energía-sabiduría original. Como en el sistema hindú, esto lleva a la inversión de la génesis.

Los cinco Budas primordiales, como las emanaciones centrales del Vacío, se consideran los progenitores de las cinco familias de deidades que forman parte del panteón budista. De este modo, surgen una variedad de divinidades en diagramas de meditación (mandalas), empleados para

28 Ver W.Y. Evans-WENTZ, El Libro Tibetano de los Muertos, Kier, Buenos Aires, 1990. 
indicar algunos principios espirituales y sus interacciones en las distintas fases de la integración psíquica. En ciertos mandalas, los Budas primordiales están representados en unión con parejas femeninas. Esto representa las cinco clases de energías-creativas, interactuando con sus cinco energías-sabidurías complementarias.

Divinidades airadas —envueltas en un halo flamígero, vistiendo macabras indumentarias con semblante repulsivo y danzando sobre cadáveresilustran el universo de las cinco sabidurías obnubiladas por las pasiones y engaños de los seres conscientes que todavía permanecen bajo la influencia de la ignorancia. Las expresiones feroces de estas divinidades ponen en evidencia el poder y la fuerza que se necesita para luchar contra el yo y sus embustes. Sus armas son empleadas para sortear las dificultades, y los seres que están tumbados a sus pies son las pasiones que han vencido. En los estadios avanzados del tantra tibetano se emplea el poder de estas divinidades airadas para dominar las partes más elementales de la mente e introducirnos en las conquistas más elevadas de la energía-sabiduría.

En el tantra budista lo femenino se correlaciona con la sabiduría y se le Ilama Prajña, en lugar de Sakti como en el tantra hindú. El principio masculino se relaciona con la habilidad de recursos. Por consiguiente, el dios y la diosa en un abrazo sexual simbolizan la unión del conocimiento-sabio con medios hábiles (figura 9).

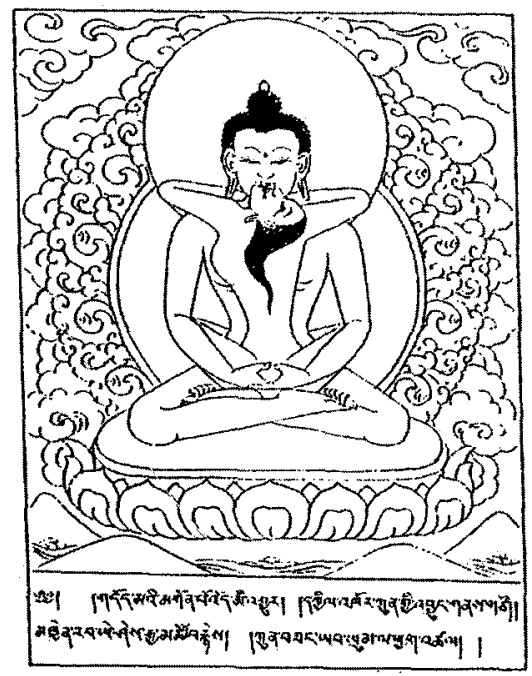

Figura 9. Samantabhadra en su forma tibetana como Buddha primordial. 
En el panteón tibetano, las deidades pueden ser visualizadas en la meditación como mentores y guardianes. Por ejemplo, para un hombre atraido por la hermosura de una mujer, se utiliza una deidad bella para transmutar esas sensaciones. Dicha diosa es conocida como dakini.

El término dakini significa, literalmente, «el que va por el cielo». A menudo las dakinis tienen una apariencia pavorosa. Con su semblante aterrador y sombrías vestimentas, nos recuerdan a Durga, la temida diosa del panteón hindú. Al unirse con la dakini, el yogui penetra en el verdadero significado de unas doctrinas demasiado profundas para desvelar sus secretos cuando el practicante se encuentra en su estado de conciencia ordinario.

Además de los cinco Budas primordiales, en un principio el tantra budista no le dio forma antropomórfica a la Realidad última no manifiesta. Sin embargo, en el siglo $x$ se introdujo en el Monasterio Nalanda en la India una forma de dios monoteísta. El Adibuddha (Buda Supremo) no crea el universo ni está separado de él. Trascendiendo la dualidad de forma y no-forma, él es la unidad de los dos y el padre de los cinco Budas. Como la Mente-Buda primordial, el Adibuddha es venerado como el «gurú básico» de las enseñanzas tántricas. Las distintas escuelas tienen representaciones diversas del Adibuddha.

Algunas veces, el Adibuddha es representado en la postura yabyum (abrazo sexual tántrico) con Prajñaparamita. Prajñaparamita, como la representación antropomórfica de la obra mahayana del mismo nombre, representa la «Sabiduría del Otro Lado». De acuerdo con el sabio hindú Nagarjuna, fue el propio Buda Shakyamuni quien compuso y depositó estas doctrinas bajo la custodia de los semidioses serpientes hasta que llegase el momento en que los hombres pudieran recibirlas ${ }^{29}$.

La literatura de la Prajpañaramita ${ }^{30}$ revolucionó el budismo, en todos los aspectos de su filosofía y religión, por la concepción básica de la vacuidad. Esta literatura engloba un grupo de enseñanzas de carácter filosófico. La escuela mahayana denominada Madhyamika, fundada por

29 Véase M_a T. ROMÁN, Análisis del problema de la conciencia en el Prajñaparamita Hridaya Sutra. Tesis Doctoral, UNED, 1994, p. 168.

30 Los textos de la Prajñaparamita alcanzan la cifra de treinta y ocho y algunos de ellos son muy extensos. Sólo un reducido número se conserva en sánscrito, el resto en traducciones chinas y/o tibetanas. 
Nagarjuna en el siglo ॥ d. de C., recogerá estas enseñanzas, y las ordenará, elaborará, desarrollará y fundamentará; y entrarán a formar parte del corpus teórico básico de la citada escuela. Su unión tántrica con el Adhibuddha expresa en forma simbólica la integración de la habilidad de recursos tántricos con la práctica mahayana de la meditación profunda sobre la Vacuidad.

Durante el entrenamiento, el practicante empieza tomando refugio en el Buda (la mente iluminada), el Dharma (la doctrina budista) y el Sangha (la comunidad de practicantes budistas). Luego, un instructor asigna al discípulo una divinidad del panteón tántrico, en base a sus necesidades individuales. Si una mujer tiene mucha ira reprimida, se le puede otorgar una de las deidades iracundas. Como un remedio homeopático, la meditación sobre la deidad iracunda purgará a la ira de su cuerpo-mente.

Una vez comprendidas las cualidades encarnadas en la deidad, el instructor faculta al estudiante a través de la iniciación a llevar a cabo diversas meditaciones sobre divinidades para que se potencien las facultades dentro de la mente del practicante. Por lo general, se requieren muchos años de entrenamiento antes de que un alumno esté capacitado para ser iniciado en un mandala de una divinidad tántrica más elevada.

\section{EL YOGA KUNDALINI}

El conocimiento y el método hindú llamado Yoga Kundalini se han transmitido de maestro a alumno desde épocas antiguas. Aunque en la corriente más importante de las antiguas prácticas tántricas hindúes esta transmisión se ha realizado en parte mediante las diversas modalidades de sexo ritualizado, también fue transmitida mediante una práctica denominada Shaktipat. Un individuo que haya despertado este poder cósmico puede mandárselo a otro individuo de distintos modos: por transferencia de pensamiento, contacto físico, cantos sagrados o mirando a los ojos al discípulo.

En la senda tántrica, un maestro es importante porque, además de su experto consejo y la enseñanza de técnicas y conocimiento, él o ella tiene esta habilidad de avivar y conducir sin problemas el despertar de la Kundalini.

En el momento en que Kundalini se despierta, su flujo gradual activa contenidos inconscientes que después pueden desbordar a la conciencia. 
Puede entrañar riesgo desafiar a cualquiera de estos hechos, ya que la fuerza puede quedar capturada o su circulación se puede distorsionar en los conductos de los cuerpos más etéreos. De este modo, pueden surgir importantes desequilibrios psico-físicos.

Existen distintas clases -o tipos- de yoga para preparar al adepto para esta intensa puesta en contacto con el inconsciente. El Hatha Yoga fortificaba y purificaba el cuerpo físico. El Bakti Yoga armonizaba la naturaleza emocional con los deseos de devoción espirituales. El Raya Yoga entrenaba la mente y la nutría de verdades filosóficas. Todas éstas llevaban al Mahayoga que se ocupaba de la activación de Kundalini.

El Yoga Kundalini, constaba de una abundante colección mitológica de símbolos, animales y una mezcolanza de dioses pre-arios y védicos, que eran visualizados en los distintos chakras durante los rituales de meditación. Se supone que el movimiento de la diosa Kundalini varía según pasa por los distintos chakras. En los diagramas hindúes de los chakras, diversos animales simbolizan estos movimientos y representan el vehículo de la divinidad primordial en cada chakra.

El cuadro que viene a continuación, nos muestra un esquema general de los chakras.

La energía Kundalini también asume un patrón de frecuencia específica en cada nivel de chakra. Estos son ilustrados en la simbología india por los mantras simientes (bija), en el centro de cada diagrama de loto. El número de pétalos de cada chakra también se refiere literalmente a su frecuencia vibracional. El chakra más elevado, por ejemplo, tiene mil pétalos; éstos representan la alta frecuencia vibracional de los planos trascendentes. La otra cara de la moneda la encarna el chakra más bajo con cuatro pétalos; éstos simbolizan la baja vibración del mundo material.

El Yoga Kundalini empieza en el primer chakra (figura 2), activando a la durmiente Kundalini, visualizando el loto del primer chakra en la base de la pelvis. Se concibe al mantra simiente (LAM) en el centro de este loto, mientras es recitado en silencio o en voz alta. Desde la forma radiante del mantra simiente, surgen en orden secuencial todos los elementos simbólicos contenidos dentro del loto. Posteriormente se observa cada divinidad y símbolo, y luego son devueltos al mantra simiente. Después se representa al mantra simiente en sí como elevándose hacia el loto del segundo chakra (figura 3 ) donde es absorbido allí por el mantra simiente de éste. 


\begin{tabular}{|c|c|c|c|c|c|c|c|}
\hline 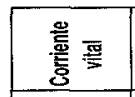 & 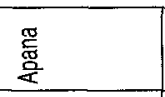 & 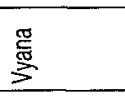 & 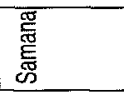 & $\begin{array}{l}\text { 愛 } \\
\text { 焉 } \\
\end{array}$ & $\begin{array}{l}\text { 㺃 } \\
\text { 吾 }\end{array}$ & & \\
\hline $\begin{array}{l}\text { 总 } \\
\text { 言 }\end{array}$ & 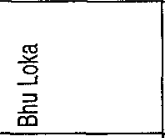 & 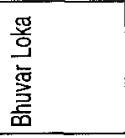 & 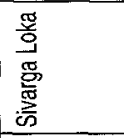 & 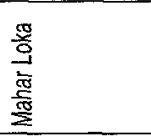 & 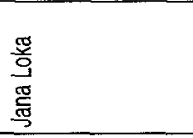 & $\begin{array}{l}\frac{\pi}{9} \\
\frac{8}{\circ} \\
\text { 음 } \\
\end{array}$ & 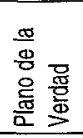 \\
\hline 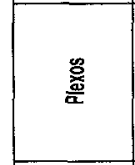 & 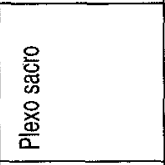 & 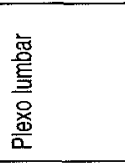 & 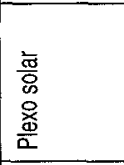 & 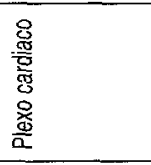 & 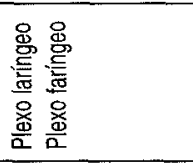 & 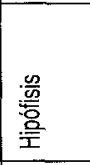 & 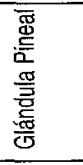 \\
\hline 雱 & 趌 & 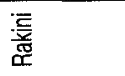 & 氶 & 雲 & 謩 & 胥 & \\
\hline 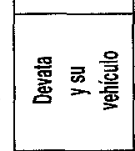 & 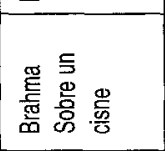 & 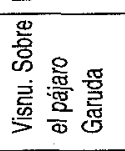 & 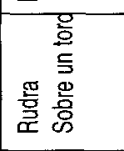 & क्ञ & 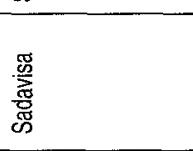 & $\begin{array}{l}\text { 름 } \\
\text { 言 } \\
\text { 品 }\end{array}$ & \\
\hline 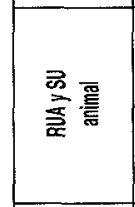 & 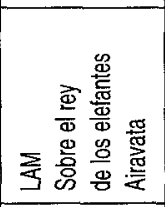 & 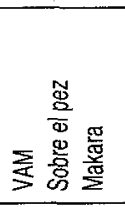 & 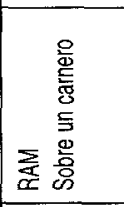 & 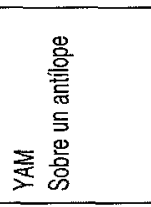 & 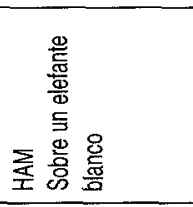 & ż & \\
\hline 哭 & 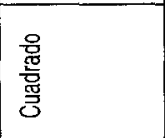 & 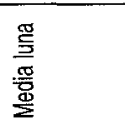 & $\begin{array}{l}\text { 옿 } \\
\text { 产 } \\
\text { 罡 }\end{array}$ & 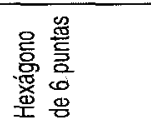 & 을 & & \\
\hline 흥 & $\begin{array}{l}\text { 을 } \\
\text { 焉 }\end{array}$ & 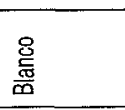 & 응 & $\begin{array}{l}\text { 을 } \\
\text { 妾 } \\
\end{array}$ & $\begin{array}{l}\text { 을 } \\
\text { 产 } \\
\end{array}$ & & \\
\hline 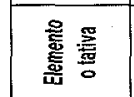 & 急 & 爱 & $\begin{array}{l}\stackrel{8}{\mathrm{~g}} \\
\stackrel{3}{4}\end{array}$ & 㕰 & 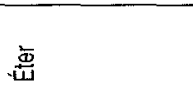 & $\begin{array}{l}\text { 謩 } \\
\text { 尊 }\end{array}$ & \\
\hline 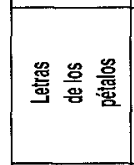 & $\begin{array}{l}\infty \\
\infty \\
\infty \\
\infty \\
\infty \\
\infty \\
\infty \\
=\end{array}$ & 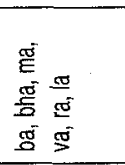 & 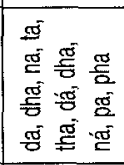 & 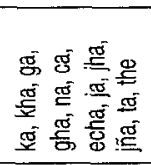 & 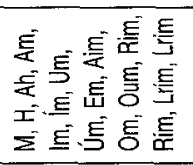 & 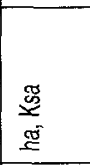 & \\
\hline 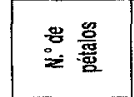 & $\sigma$ & $\infty$ & 으 & $\simeq$ & $\subseteq$ & $\sim$ & $\stackrel{8}{\circ}$ \\
\hline 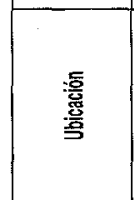 & 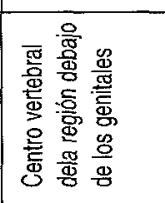 & 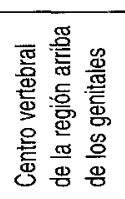 & 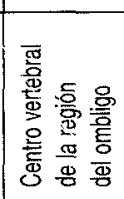 & 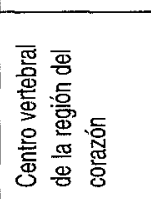 & 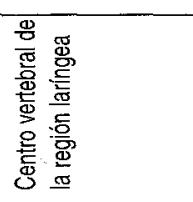 & 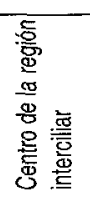 & \\
\hline 宕 & 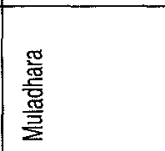 & 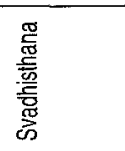 & 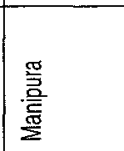 & 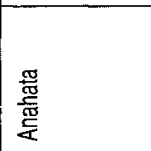 & 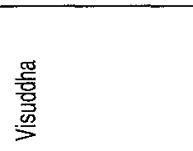 & 营 & 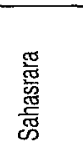 \\
\hline
\end{tabular}


Al segundo chakra se lo visualiza debajo del ombligo. Conforme se recita el mantra simiente en su centro, los elementos del segundo chakra surgen y se medita sobre ellos. Finalizado esto, los contenidos son reintegrados al mantra simiente, el cual su vez asciende al tercer chakra (figura 4) en el plexo solar.

Esta actuación se repite hasta el séptimo chakra (figura 8), a partir del cual la conciencia del practicante penetra en el vacío celestial de la conciencia pura. El yogui persiste en concentrar su conciencia en este estado. El ritual de meditación se completa recreando el cuerpo-mente.

\section{LAS DOS VIASS DEL TANTRA}

\section{El tantrismo de la derecha}

En el tantrismo se han distinguido siempre dos corrientes, denominadas, en términos técnicos, de derecha y de izquierda.

La vía de la derecha reposa sobre una concepción de seis centros (chakras), de energía situados en el interior del cuerpo humano y representados por otros taritos lotos, desde la base del tronco hasta el cráneo, en forma de círculos, conectados entre sí por conductos y coronados por un séptimo centro, en la parte superior del cráneo; el "círculo" inferior, en la base del tronco, se encuentra la diosa, figurada en forma de serpiente enroscada (kundalini), símbolo de la energía cósmica inconsciente; en el centro más elevado se halla la sede de Siva.

La técnica del tantra, inspirada en las técnicas yogas de concentación, consiste en llegar a despertar la Kundalini, hacerla subir poco a poco por la vena gruesa de la columna vertebral; a través de los círculos o chakras (Muladhara, Svadhistana, Manipura, Anahata, Visuddha) correspondientes a las potencias materiales de la vida humana hasta el sexto chakra (Ajna), que es el de la vida mental, y, por último, hasta el séptimo (Sahasrara) el de la consciencia, en lo alto del cráneo, donde todas las energías acarreadas por la Kundalini, van a unirse con Siva. Ésta es la felicidad suprema. Como dice poéticamente una obra tántrica, la Descripción de los seis círculos:

«Después de haber bebido el néctar excelente color de laca que emana del supremo Siva, la gran fuente de felicidad eterna, Kundalini la bella se reintegrará por la vía del kula (la abertura del brahman, situada en la coroni- 
lla) al círculo de la base. El yogui de pensamiento firme, con un raudal de néctar celeste que ha gustado gracias a la tradición del Yoga, hará libaciones a las divinidades que tienen su asiento en el Vaso del Huevo cósmicon: Ia operación termina, así, en una especie de sacrificio al cosmos. Recibe el nombre de Laya-yoga o «yoga de absorción»; cabe ver en ella, naturalmente, una sublimación del acto carnal» ${ }^{31}$.

\section{El tantrismo de la izquierda}

El tantra «de la izquierda», por su parte, sólo recurre a los métodos del yoga para adoptar una actitud opuesta al tantrismo de la derecha: la vía hacia la iluminación es consecuencia del libre curso dado, por lo menos temporalmente, a las sensaciones incluso a las pasiones. Es una suerte de estimulación erótica, con escenificaciones individuales o colectivas de realización sexual, para llegar por último a experimentar la vanidad de estos goces, a "sacudirse" sus tiránicos grilletes y a derrocar de ese modo el yo, que se apoya en una conjunto de deseos. Como subraya Renou: «se trata de una suerte de homeopatía religiosa, cuya técnica es de base mágica» ${ }^{32}$.

A este cuerpo que nos ata se le pide la libertad, del mismo modo, dice el Kularnavatantra que el hombre caído del suelo debe levantarse con la ayuda del suelo, de la misma manera que se necesita una espina para retirar una espina clavada en el pie.

Estos principios han dado lugar a diferentes prácticas que, confundidas erróneamente con vulgares orgías, causaron la indignación de los eruditos occidentales. Siendo el sexo el rasgo más evidente de la enajenación física, era, no obstante, normal, en las perspectivas de la invasión tántrica de los valores, que los métodos y los ritos sexuales ocuparan un puesto de primer orden en la vía hacia la liberación.

El tantrismo, por su exaltación de la energía cósmica, debía desarrollarse en estrecha relación con la idea de la sakti, del principio femenino activo y creador por medio del cual, el Dios, sin salir de su reposo eterno, pudo emanar el universo. La unión sexual con la mujer pasa a ser entonces la realidad simbólica de la comunión con la fuerza suprema que anima a todo el cosmos.

\footnotetext{
31 Louis RenOu, El hinduismo, Paidós, Barcelona, 1991, p. 74.
}

32 Ibid., p. 75. 


\section{BIBLIOGRAFÍA}

AValon, A.: The serpent power, Ganesh, Madras, 1953.

- Principles of Tantra, Ganesh, Madras, 1951.

BLAY, A.: Tantra Yoga, Iberia, Barcelona, 1986.

Blofeld, J.: El budismo tibetano, Martínez Roca, Barcelona, 1980.

CONZE, E.: Breve historia del budismo, Alianza, Madrid, 1983.

ElIADE, M: Yoga, inmortalidad y libertad, La Pléyade, Buenos Aires, 1988.

Evans-WENTZ, W.Y.: Yoga tibetano y doctrinas secretas, Kier, Buenos Aires, 1975.

- El Libro Tibetano de los Muertos, Kier, Buenos Aires, 1990.

- El Libro Tibetano de la Gran Liberación, Kier, Buenos Aires, 1977.

EVolA, J.: Le Yoga tantrique. Sa métaphysique ses pratiques. Fayard, Paris, 1971.

FELICE, P. de: Venenos sagrados. Embriaguez divina, Felmar, Madrid, 1975.

GLASENAPP, H.von: El budismo una religión sin Dios, Barral, Barcelona, 1974.

- Misterios budistas, Ediciones Esotéricas, Buenos Aires, 1974.

GovinDA A.: Fundamentos de la mística tibetana, Eyras, Madrid, 1980.

Henderson, J.L. and OAKES, M.: The Wisdom of the Serpent, Collier Books, New York, 1971.

Mourre, M.: Religiones y filosofias de Asia, Zeus, Barcelona, 1962.

PANDIT, M.P.: Kularnava Tantra: rito de las cinco cosas prohibidas, Eyras, Madrid, 1980.

PARAIN, B. (dir.), El pensamiento prefilosofico y oriental en Historia de la Filosofía, Siglo XXI, Madrid, 1984, Vol. I.

PUECH, H.Ch. (dir.), Las religiones en la India y en el Extremo Oriente en Historia de las Religiones, Siglo XXI, Madrid, 1985, Vol. IV.

Rawson, P.: Tantra: The Indian Cult of Ecstasy, Avon, New York, 1973.

RENOU, L.: El hinduismo, Paidós, Barcelona, 1991.

RIVIĖRE, J.: El pensamiento filosófico de Asia, Gredos, Madrid, 1960.

- El yoga tántrico, Kier, Buenos Aires, 1978.

Román LóPEZ, M.T.: Diccionario de las Religiones, Alderabán, Madrid, 1996.

- «Buda: un personaje para la historia del antiguo oriente», Espacio, Tiempo y Forma, UNED, Madrid, 1994.

- "La magia hindú y su proyección hacia Occidente en el mundo antiguo», Espacio, Tiempo y Forma, UNED, Madrid, 1995.

SANGHARAKSHITA, El tantra: su simbolismo y sus prácticas, Fundación Tres Joyas, Valencia, 1995.

SCHUHMACHER, S. y WOERneR, G. (dirs.): Diccionario de la sabiduría oriental, Paidós, Barcelona, 1993.

SivanANDA, K.: Tantra: Yoga de realización, Instituto Tantra, Calonge-Girona, 1978.

Sivananda, S.: Tantra Yoga. Nada Yoga. Kriya Yoga, Kier, Buenos Aires, 1979.

- Kundalini yoga, Kier, Buenos Aires, 1971.

TsULTRIM, Geshe L.: El adiestramiento mental y los doce vínculos de originación interdependiente, Dharma, Novelda (Alicante).

Tuccl, G.: Teoría y práctica del mandala, Dédalo, Buenos Aires, 1975.

TRUNGPA, C. y GUENTHER, H.V.: El amanecer del tantra, Kairós, Barcelona, 1976.

Rahula, W.: Lo que el Buddha enseñó, Kier, Buenos Aires, 1990.

YESHE, Lama, Introducción al tantra, Dharma, Novelda (Alicante), 1988.

ZIMmER, H.: Filosofías de la India, Eudeba, Buenos Aires, 1979. 